\title{
Modos de Ser na Era Virtual: Um olhar da Psicologia Fenomenológico-Existencial
}

Modos de Ser en la Era Virtual: Una mirada de la Psicología Fenomenológico-Existencial Ways of Being in the Virtual Era: An Existential-Phenomenological Psychology approach

ORCID: http://orcid.org/0000-0002-4116-8614

Universidade Federal do Piauí, Piauí/Brasil

Elza Maria do Socorro Dutra

ORCID: http://orcid.org/0000-0003-0225-9836

Universidade Federal do Rio Grande do Norte, Rio Grande do Norte/ Brasil

Melina Séfora Souza Rebouças

ORCID: http://orcid.org/0000-0002-4920-4202

Universidade Federal do Rio Grande do Norte, Rio Grande do Nortel Brasil

Declaração de Direito Autoral

A submissão de originais para este periódico implica na transferência, pelos autores, dos direitos de publicação impressa e digital. Os direitos autorais para os artigos publicados são do autor, com direitos do periódico sobre a primeira publicação. Os autores somente poderão utilizar os mesmos resultados em outras publicações indicando claramente este periódico como o meio da publicação original. Em virtude de sermos um periódico de acesso aberto, permite-se o uso gratuito dos artigos em aplicações educacionais e científicas desde que citada a fonte conforme a licença CC-BY da Creative Commons.

\section{Resumo}

O presente artigo tem como objetivo pensar sobre a tecnologização do mundo contemporâneo e desenvolver algumas reflexões sobre os modos de ser na era virtual, partindo do olhar da Psicologia Fenomenológico-Existencial, que toma como base a ontologia do filósofo Martin Heidegger. Neste sentido, os autores trazem breves apontamentos sobre a analítica da existência e a era da técnica, seguida da discussão sobre a cotidianidade do homem contemporâneo na era virtual, finalizando com a reflexão do Cuidado e os modos de ser aí presentes. Ao realizar esta breve análise, foi possível observar o quanto o ciberespaço tornou-se mais um local dentre tantos outros de desvelamento de diferentes modos do Dasein de ser-com o outro, ora de modo próprio ou impróprio, se aproximando ou se distanciando de sua experiência e do outro, por exemplo. Também foi discutido como a técnica nos substitui em nosso cuidar de ser e a presença cotidiana do modo de cuidado indiferente nas relações virtuais. Diante disso, Heidegger aponta o silêncio e a serenidade como possibilidades ao Dasein de escutar-se e aproximar-se de suas solicitações mais singulares e próprias. Olhar este fenômeno tão presente no dia-a-dia do homem contemporâneo, sob o olhar da perspectiva heideggeriana pode nos auxiliar a melhor compreender os impactos de tamanha tecnologização na cotidianidade do ser-aí.

Palavras-chaves: Fenomenologia heideggeriana; Era virtual; Técnica; Cuidado.

\section{Resumen}

El presente artículo tiene como objetivo pensar sobre la tecnología del mundo contemporáneo y desarrollar algunas reflexiones sobre los modos de ser en la era virtual, partiendo de la mirada de la Psicología Fenomenológico-Existencial, que toma como base la ontología del filósofo Martin 
Heidegger. En este sentido, los autores traen breves apuntes sobre la analítica de la existencia y la era de la técnica, seguida de la discusión sobre la cotidianidad del hombre contemporáneo en la era virtual, finalizando con la reflexión del Cuidado y los modos de ser ahí presentes. Al realizar este breve análisis fue posible observar cuánto el ciberespacio se volvió más un lugar entre tantos otros de desvelamiento de diferentes modos del Dasein de ser-con el otro, o de modo propio o inapropiado, aproximándose o distanciándose de su experiencia y por el otro, por ejemplo. También se discutió cómo la técnica nos sustituye en nuestro cuidar de ser y la presencia cotidiana del modo de cuidado indiferente en las relaciones virtuales. Ante todo, Heidegger apunta el silencio y la serenidad como posibilidades al Dasein de escucharse y acercarse a sus peticiones más singulares y propias. Mirando este fenómeno tan presente en el día a día del hombre contemporáneo, bajo la mirada de la perspectiva heideggeriana, puede ayudarnos a comprender mejor los impactos de tal tecnología en la cotidianidad del ser-ahí.

Palabras claves: Fenomenología heideggeriana; Era virtual; Técnica; Cuidado.

\begin{abstract}
The present article aims to think about the technologization in contemporary world and develop some reflections on the ways of being in the virtual age, starting from Phenomenological-Existential Psychology perspective, with Martin Heidegger's ontology. In this sense, the authors bring brief notes on the analytic of existence and the era of technique, followed by the discussion about everyday life of contemporary man in the virtual age, ending with a reflection about Care in Heidegger's Ontology and the ways of being there in the present. Carrying out this brief analysis it was possible to observe how much cyberspace has become yet another place among so many others to unveiling Dasein's different ways of being-with the other, sometimes in a proper or improper way, approaching or distancing himself from his experience and from others around him. It was also discussed how technique replaces us in our caring of being and also discussed about everyday presence of the indifferent care mode in virtual relationships. In view of this, Heidegger points to silence and serenity as possibilities for Dasein to listen to and approach his most singular and proper requests. Look at this phenomenon so present in contemporary man's daily life, under the perspective of the Heideggerian perspective, can help us to better understand the impacts of such technology on daily life of beingthere.
\end{abstract}

Keywords: Heideggerian phenomenology; Virtual era; Technique; Care.

\section{Introdução}

As interações sociais virtuais são uma realidade na cotidianidade do homem contemporâneo e vêm causando grandes transformações nos modos como nos relacionamos com os outros e com o mundo. Diante disso, surgem questionamentos dos mais variados, entre os quais: Que fenômeno é este, o da virtualidade? Quais os impactos para as nossas vidas? E para as gerações futuras? Como compreender melhor tais fenômenos, considerando que nos encontramos, todos, lançados neste processo em construção de novas formas de socialização?
Para ajudar na compreensão do fenômeno da virtualização nos amparamos no olhar da Psicologia FenomenológicoExistencial, de inspiração heideggeriana, que toma como base a ontologia do filósofo Martin Heidegger, para pensar as questões ônticas do homem em sua cotidianidade (Dutra, 2008; Feijoo, 2011; Morato, 2013; Sá, 2002). Nessa perspectiva, só é possível compreender um fenômeno humano considerando o horizonte histórico em que este se encontra lançado. Tendo em vista essas ideias, o objetivo deste artigo é pensar sobre a tecnologização do mundo contemporâneo e desenvolver algumas reflexões sobre os modos de ser na era virtual. 


\section{Breves Apontamentos sobre a Analítica da Existência e a Era da Técnica}

Filósofo da Analítica da Existência e considerado um dos grandes pensadores do século XX, Martin Heidegger nasceu em Messkirch, na Alemanha, estudou na universidade de Freiburg-im-Breisgau e foi aluno de Edmund Husserl, criador do método fenomenológico. Em 1927 publicou sua maior obra "Ser e Tempo", deixando um grande legado e muitos questionamentos a serem aprofundados e compreendidos (Stein, 2011). Em face do seu rebuscamento e profundidade, é importante lembrar, antes de tudo, que interpretar suas ideias é tarefa complexa e desafiadora. Portanto, nossa intenção aqui é ensaiar uma aproximação com seus saberes, tecendo possibilidades de interlocuções com o fenômeno da virtualidade.

Inovação e contemporaneidade são as palavras que descrevem bem as ideias trazidas por Heidegger, pensador à frente de seu tempo, que trouxe grandes ideias para a época, e cujas reflexões continuam atuais e contemporâneas. Embora Husserl tenha fornecido uma base teórica a Heidegger, este trilhou seu caminho de forma independente, desenvolvendo uma ontologia própria e com características distintas da fenomenologia husserliana. Um aspecto notório de sua Analítica Existencial é o modo como evita termos com concepções determinísticas, criando seu próprio vocabulário, com uma terminologia ontológica capaz de comunicar suas ideias e afetações em torno de sua questão principal: qual o sentido do Ser?

Heidegger (1927/1993) aponta para uma diferença ontológica fundamental entre Ser e ente. O ente é tudo o que está no mundo, tudo o que se conhece. Já o ser-aí é o único ente que possui uma postura compreensiva do mundo e de si mesmo (pré-compreensão). Partindo deste pressuposto básico, ao ser do homem Heidegger atribuiu o nome: Dasein (ser-aî) ou ser-no-mundo que, para além de uma nomenclatura, implica uma integração do ser do homem, não mais cindido ou naturalizado, como na metafísica clássica, mas como um todo, superando visões dicotômicas: corpo-mente, consciente-inconsciente, subjetividade-objetividade. E assim, afirma o projeto do ser-do-homem como Dasein ontológico, cuja representação como "subjetividade da consciência" é superada (Heidegger, 1927/1993).

Partindo de uma crítica à metafísica clássica, Heidegger assume a perspectiva da temporalidade como fio condutor da compreensão do ser, e traz a importância da hermenêutica enquanto caminho para sua interpretação e compreensão.

A fenomenologia heideggeriana visa, portanto, interpretar o que se manifesta aí. E essa interpretação não visa encontrar respostas prontas, explicações causais, mas tão somente compreender os modos "como" os fenômenos se manifestam, enfatizando a relatividade e a provisoriedade dos saberes.

\section{Para Heidegger (1927/1993) o Dasein} possui características ontológicas: ser-nomundo, ser-com-o-outro e ser-para-a-morte. Homem e mundo coexistem e, sendo-nomundo, o Dasein é mundano, é um poder-ser aberto às possibilidades que se desvelam e vêm ao seu encontro no mundo. Isso nos conduz à noção do homem como ser-com-os-outros. Imerso em um contexto de relações, o ser do homem está sempre com-o-outro, não podendo existir isoladamente, mesmo que não queira se relacionar com ninguém. Ainda assim, estará tecendo um tipo único de relação, já que não há como subsistir para si mesmo, de forma isolada (Critelli, 2006). O Dasein é sempre projeto, buscando sua realização e sempre em pendência com alguma coisa. Vive na impessoalidade, evitando sua única e inexorável certeza: a morte; por isso, a esta característica, Heidegger atribui o termo serpara-a-morte. Desta maneira, o Dasein está lançado neste mundo de imprevisibilidades e possibilidades, podendo escolher como realizar-se. E nesta busca, vai atribuindo sentidos e significados às suas experiências.

Heidegger (1927/1993) atesta que a história do homem moderno é a história do 
esquecimento do ser, na medida em que o ser foi igualado ao ente. A busca da metafisica ocidental sempre foi descobrir o que era o ser e, nessa busca, o ser foi entificado, isto é, objetivado, representado, definido. Desse modo, a essência dos entes está na representação de um objeto para um sujeito pensante e, consequentemente, o real passa a ser visto a partir das possibilidades representativas da razão. A modernidade, com isso, é marcada pelo esforço de definir e controlar o ser por meio do cálculo. Diante disso, a técnica na modernidade possui o sentido de reduzir o mundo àquilo que é passível de medida, previsão e controle.

$\mathrm{Na}$ segunda fase do seu pensamento, Heidegger se dedica a discorrer sobre o horizonte da técnica, com o intuito de pensar sobre os significados de viver em um mundo científico-tecnológico, interrogando sobre as suas possibilidades e os seus perigos (Duarte, 2010). Para Heidegger a técnica constitui o nosso ser-no-mundo na medida em que esta é a nossa herança e o nosso envio/destino (Cordeiro, 2014). Isso significa que a técnica, tal como pensada por este filósofo, não se refere somente a um aparato instrumental, isto é, a um conjunto de meios para se chegar a um fim. Esta é apenas a sua determinação instrumental e antropológica. A técnica, em sua essência, refere-se ao horizonte histórico ao qual estamos lançados e que marca o nosso modo de pensar, agir e de nos relacionarmos com o mundo e com os outros.

Nesse sentido, pensar a essência da técnica significa compreendê-la em seu sentido originário como téchne. A técnica enquanto téchne refere-se a um saber não tematizado que abre acesso às coisas, segundo o modo de ser das próprias coisas. É deixar que o ente apareça e se desvele ao seu próprio modo. Aproxima-se do ofício do artesão que, ao acompanhar o próprio rumo da natureza, antevê a possibilidade de produzir um artefato ou utensílio. E produzir (poiesis), do grego producere, refere-se a conduzir algo à vista, libertá-lo, permitir que se manifeste (Cordeiro, 2014). Na técnica moderna o desvelamento dos entes não acontece como um produzir guiado pela própria natureza, mas como uma exploração que impõe à natureza a aparição dos entes. Nesse modo, o ente é provocado e desafiado a aparecer para ser utilizado como fonte de reserva, como matéria-prima disponível. Assim, ao desafiar a natureza, controla-se a possibilidade de manifestação das coisas.

No entanto, Heidegger (1954/2010) alerta que o desencobrimento da técnica moderna não é um simples feito do homem. $\mathrm{Na}$ verdade, o que o homem faz é responder ao apelo do desencobrimento, que nesse caso é o de dispor da natureza. De acordo com Duarte (2010), isso significa dizer que o homem não é o agente e nem o controlador da técnica, mas alguém que é constantemente demandado por esta; isto é, o homem seria, nesses termos, apenas um "funcionário" da técnica. $\mathrm{Na}$ modernidade, portanto, o modo de desencobrimento que rege e encaminha o homem é o da disponibilidade. Nesse modo de desencobrimento, o homem e a natureza são tidos como recursos que, se bem explorados e transformados, geram conhecimento útil, progresso, qualidade de vida, entre outros. Tudo o que é real subiste para ser melhorado, desenvolvido, previsto e calculado. Essa é a marca do nosso tempo.

Ao questionar sobre a técnica e compreendê-la enquanto destinamento histórico, Heidegger buscava propor uma relação mais livre com a técnica, de modo que o homem não se tornasse escravo desta. O mesmo enfatizava que o perigo da essência da técnica moderna residia no fato de ser pensada como o único modo possível de desocultamento e, assim, ofuscar outros modos possíveis, como o da téchne, por exemplo. No intuito de não nos perdermos totalmente nesse horizonte técnico marcado pelo pensar objetivante e calculador, Heidegger propõe outra atitude diante das coisas, a qual ele denominou de serenidade. Tal atitude refere-se a uma distinta relação com o ser, não mais confundido ou igualado ao ente. A serenidade seria marcada por um pensamento meditante, que não calcula resultados ou que ofereça soluções práticas, mas que se caracterize por 
uma escuta e atenção solícita a pensar o ser em seu envio historial. Seu apelo é para que tenhamos uma relação livre com o próprio ser e isso exige que possamos refletir sobre o que está mais próximo, e assim, nos abrirmos ao mistério que guarda a livre correspondência entre o homem e o ser (Heidegger 1954/2010). Segundo Critelli (2002), corresponder a um novo apelo do ser exige uma abertura para o que é inaudito e desconhecido.

O homem contemporâneo está habituado a ouvir somente aquilo para o que há explicação, pois em seu modo técnico de ser/existir é inadmissível haver um fenômeno que não possa ser disposto, assegurado e conceituado. Isso aponta para uma questão importante: a técnica moderna não sabe lidar com a condição do ser de esvair-se, isto é, de revelar-se e de ocultar-se. Nesse sentido, apesar dos esforços do homem moderno, muitos fenômenos fogem à possibilidade de medição e explicação. De acordo com Cordeiro (2014), o homem moderno habita sem poesia, e ser poético significa poder ver, numa mesma unidade, a aurora e o crepúsculo, poder ver no familiar, o estranho. Em outras palavras, ser poético é acolher o mistério.

Diante destas breves explanações sobre as ideias de Heidegger, como pensar as provocações deste filósofo em tempos de globalização, virtualização das relações humanas, de acesso ilimitado a informações, etc.? Quais as implicações da técnica moderna na trama de sentidos e significados que se revelam nos modos de ser da contemporaneidade?

\section{A Cotidianidade em Clicks}

São inegáveis os benefícios da tecnologia e da virtualidade, bem como dos seus avanços. A positividade trazida à cotidianidade é tamanha que se torna incontável e imensurável, pois apresentou ao homem e à sociedade, um mundo totalmente novo, flexível e, como diz um famoso slogan, "sem fronteiras". Basta olhar ao redor, ou mesmo apenas em um click, para se encontrar depoimentos dos mais variados, a respeito de experiências positivas na internet: superação das barreiras geográficas, economia de tempo, de papel, de recursos, agilidade na resolução de problemas, acessibilidade de informações variadas, maior produtividade, aproximação de pessoas que estão distantes. Tudo está conectado e globalizado.

Uma parcela significativa da sociedade global contemporânea está conectada e atualizada ao novo que se mostra através da tecnologia, na cotidianidade, tendo os usuários da internet, a possibilidade de realizar inúmeras atividades ao mesmo tempo, mais ainda quando está com dispositivos móveis, como celular, tablet, etc.), em que a velocidade para se conectar multiplica-se; ao mesmo tempo em que manda um e-mail para a Austrália, fala em tempo real pelo aplicativo Whatsapp com alguém no Japão, baixa fotos no computador, realiza compras, faz uma transferência bancária online, escuta música, joga e conversa no Whatsapp e no Skype com pessoas que podem estar tanto perto como longe. Tudo em apenas alguns clicks, sem sair de onde estiver: em casa, no trabalho, na praça, no shopping, andando a pé, no ônibus ou mesmo, no avião!

Este seria um retrato do homem contemporâneo, conectado, virtualizado e tecnologizado. Esta positividade é apenas uma mostra das inúmeras possibilidades inauguradas pela internet; contudo, do mesmo modo que a virtualidade traz benefícios ao sercom, igualmente traz questões que requerem reflexões mais acuradas.

Como uma herança da Revolução Industrial e uma tendência da globalização e da tecnologia, a força humana vem sendo substituída por máquinas e os processos da vida diária estão adaptando-se aos recursos digitais e virtuais: transporte, comunicação, inclusive, o estar-com-o-outro. Isso quer dizer que a tecnologia adentrou não apenas a esfera de produção e de trabalho, mas a esfera das interações humanas, que não são mais as mesmas. O que se observa nos dias de hoje são cada vez mais pessoas "conectadas" / "online" na Internet, em seus dispositivos móveis, com seus gadgets e aplicativos diversos (facebook, 
whatsapp, instagram, etc.) em busca de algo, busca que se mostra de diferentes maneiras no ciberespaço, em redes sociais,blogs, através de um volume gigantesco de publicações e compartilhamento de conteúdos (fotos instantâneas, selfies - fotos da própria pessoa, conhecidas também como egoshots ou autoretratos), "posts", vídeos, depoimentos pessoais, na busca por novos amigos ou namorosvirtuais, diários íntimos, tudo no ambiente virtual, havendo uma grande facilidade em conectar e desconectar, adicionar e deletar, estar perto e longe, tudo ao mesmo tempo.

Neste universo paralelo que é o virtual acontecem trocas para todos os fins: profissionais, acadêmicas, culturais, sociais, comerciais e pessoais. São milhares de arquivos trocados em tempo real, contendo imagens, vídeos, e-mails, opiniões e informações pessoais. E nesse espaço virtual, embora não palpável pelos sentidos humanos de olfato, tato ou paladar, as experiências acontecem via audição e visão. Através destes sentidos, possibilitam-se tantas experiências quanto se ocorressem no presencial, com a diferença básica que há mediadores para que aconteçam: a internet e a máquina (seja o computador, notebook, tablets, celular).

No cenário social de tais avanços, o homem convive com a perseveração das desigualdades sociais, corrupção, competitividade e violência, fatores que delimitam seus passos no espaço físico, concreto. Levantam-se grades de proteção, câmeras que tudo controlam; vidros e portas fechadas com o medo generalizado do imprevisível, do indesejado, do que angustia. E, para tornar este cenário ainda mais complexo, temos os meios de comunicação em massa, a publicidade e os interesses das grandes indústrias, apresentando ao homem modelos ideais de identificação: juventude, beleza, perfeição, riqueza e até mesmo, ostentação, associados à ideia de felicidade, realização e sucesso.

Esses delineamentos trazem demandas que afetam os modos de ser do homem e clamam por sua atenção para serem atendidas de imediato. Em meio a tantos estímulos, afetações e necessidades geradas pela informatização e tecnologização do cotidiano, inaugura-se uma nova fase na existência contemporânea, em que o contato e a interação presencial estão cedendo lugar ao modo de estar conectado. Isso nos leva a um segundo questionamento: Estaria, a internet, no topo da pirâmide das necessidades do homem moderno, no sentido de "ter que estar conectado"? Ora, sabemos que o homem está mais exposto ao contato-com virtual. Se antes das Tecnologias de Informação e de Comunicação (TIC's) o homem tinha de se lançar no mundo para fazer coisas e encontrar seus semelhantes, hoje ele faz praticamente tudo virtualmente, em clicks, se abrindo a dispositivos técnicos e artefatos criados e utilizados por ele mesmo (Zuhandenheit) - o computador, os sites, os links - que mediam suas conexões com o mundo e com o outro.

A velocidade acompanha o homem contemporâneo no vai e vem dos clicks. Está em um site de compras, e em frações de segundos, acessa um processo judicial, acessa o resultado de seus exames, recebe o e-mail de um grande amigo e checa a vida de seu vizinho. Um minuto. Este é o tempo necessário para a realização de tais tarefas que despertam sentimentos paradoxais e intensos. Aqui, é possível vivenciar rapidamente emoções intensas que, pela natureza veloz da rede, acabam sendo marginalizadas, esquecidas, levadas ao ocultamento e diluídas pela curiosidade e pelo impulso irrefletido para o próximo click, que traz a próxima experiência. Isso retrata a preocupante possibilidade de a velocidade restringir de algum modo a chance do homem aprofundar-se, de se abrir ao outro com profundidade, pois tudo é facilitado e ágil: as ações, as reações, as demandas, as cobranças, os apelos do mundo virtual. Disso resulta que poucos param para realmente pensar no que postam e publicam em rede. Nesse ritmo frenético, são expostos fragmentos privados de vidas que se tornam públicas em frações de segundos. Tudo se torna passível de publicação. 
De acordo com Sibilia (2008), as redes presenteiam seus usuários com um "festival de vida privada", com um excesso de exibição e "espetacularização da intimidade" (p. 50). O slogan 'sorria, você está sendo filmado' generalizou-se para qualquer lugar, em qualquer momento. Há sempre alguém com uma câmera para registrar o que está se passando, queira você ou não. Se por um lado prevalece a efemeridade e a descartabilidade, por outro, nunca registramos tantos momentos e consumimos tanta informação em tão pouco tempo. Armazenar uma quantidade gigantesca de informação e impossível de ser revisitada em profundidade não a torna menos efêmera.

Rendeiro (2011) aponta que a atitude desse novo homem de rever sua vida, com fotos, fragmentos, lembranças e editando imagens, evidencia o medo do esquecimento. Desse modo, o homem consome de um modo virtual coisas que não precisa, mas que pela força do "todos nós", do que todos fazem, do que todos compram e consomem, insiste em ter, ou registrar, expressando suas interações e vínculos de forma visível e veracizados por testemunhas ocultas e invisíveis, mas presentes.

$\begin{array}{cccr}\text { Tal cenário é } & \text { denominado pelo } \\ \text { sociólogo } & \text { Lipovetsky } & \text { (1983) }\end{array}$
hipermodernidade. A hipermodernidade caracteriza-se por uma exacerbação das características da modernidade, tais como: o individualismo, a separação espaço/tempo e a informação como mediadora e orientadora das relações sociais. Nesse modo de vida os acontecimentos são levados ao extremo, isto é, tudo torna-se excessivo: consumo, prazer, informação, tecnologia, estilos de vida, trabalho, etc. E nesse modo de acesso ilimitado a coisas e pessoas, o homem precisa ser o mais ágil possível para viver um pouco de tudo. $\mathrm{O}$ homem hipermoderno, portanto, vive de prazeres imediatos, de relações efêmeras, de presentes instantâneos.

Para Lipovetsky (2004), a sociedade hipermoderna é superficial e frívola e se submete às logicas da moda: da renovação e do efêmero, da sedução e da diferenciação, impondo a normatividade através da espetacularização da vida cotidiana. $\mathrm{O}$ processo de busca pelo novo acarreta em uma sociedade regida pelo imediatismo, onde tudo acontece em um click. Na mesma medida, é acometida pelos efeitos colaterais: instabilidade, precariedade, vulnerabilidade e insegurança. É a era em que a promessa de felicidade está a um só click, mas também é a era do sofrimento, da depressão, da medicalização e do vazio.

Tais características da hipermodernidade trazem para o homem uma perda do sentido de si. É um homem desorientado e fragmentado e que depende cada vez mais dos próprios recursos para construir a si mesmo, isto é, da sua capacidade pessoal de organizar as informações recebidas. Bauman (1998) comenta que o homem contemporâneo tem mais liberdade, mas pouca segurança individual, na medida em que não encontra mais referências nas quais possa se agarrar. Não é que essas referências não existam, mas elas são inúmeras.

O homem contemporâneo é um sujeito em crise e que apresenta uma experiência subjetiva empobrecida, na medida em que essa experiência é mediada pelos meios de comunicação de massa e pelas novas tecnologias, o que faz com que as informações recebidas pelo sujeito cheguem muitas vezes incompletas, superficiais, fragmentadas e distorcidas. O homem vem perdendo, assim, a sua capacidade de temporalizar e de tecer sua trama histórica, na medida em que fica à mercê de momentos passageiros, do prazer imediato e da busca de uma independência e liberdade a todo custo. É um homem que rompe com as tradições, mas que não tem condições de construir um futuro seguro. É um homem desenraizado, vazio e em profundo sofrimento (Portela, 2008).

Trazendo para a discussão o horizonte da técnica prenunciado por Heidegger, o mesmo irá afirmar que o pensamento calculante que rege a técnica moderna tem empobrecido o pensamento do homem. Tal empobrecimento não diz respeito à perda da capacidade de pensar, tendo em vista que esta é a época dos grandes feitos do pensar humano, como 
mencionado anteriormente, mas Heidegger alerta para a falta de reflexão deste pensar (Heidegger, 1959). Devido ao avanço tecnológico, procura-se o caminho mais fácil e rápido para se obter um conhecimento e, com a mesma facilidade e rapidez, tudo é esquecido, ou sequer armazenado. Esse conhecimento é esquecido porque não foi refletido, e sim calculado. O pensamento meditativo, diferente do calculante, exige esforço e treino e também requer tempo, ou seja, assim como o lavrador, é preciso aguardar que a semente desponte e amadureça. No entanto, como vimos, o tempo da técnica moderna é outro.

Duarte (2010), baseando-se no pensamento de Heidegger, traz a hipótese de que a realidade virtual produzida pelo avanço tecnológico da informática assume o lugar de fundo de reserva, de matéria-prima destinada à exploração. A realidade virtual nada mais é do que a informação veiculada tecnicamente, isto é, informações transmitidas em tempo real por diversos meios tecnológicos. O problema da transformação da realidade em informação é o achatamento e homogeneização do que é transmitido de tal modo que a informação produzida demanda e acumula mais informação, não tendo, portanto, nenhuma finalidade a não ser a sua própria perpetuação. Na realidade virtual os acontecimentos não têm um lugar, considerando que os mesmos são diluídos na mesma hora em que a máquina informacional os toma e os propaga.

Sobre essa questão, Heidegger (1954/2010) aponta que o excesso de informação tem produzindo uma cegueira diante dos fenômenos e que o pensar moderno transformou-se num calcular sem visão. A falta de meditação tem levado o homem a um profundo desenraizamento, isto é, o homem perdeu suas raízes, seus valores. Seu modo de habitar a terra mudou. É um homem sem morada e que tem se afastado cada vez mais de suas origens, como o mesmo afirma:

A cada hora e a cada dia estão mais presos ao rádio e à televisão. $\mathrm{O}$ cinema transporta-os semanalmente para os domínios invulgares, frequentemente apenas vulgares, da representação que simula um mundo que não o é (...). Tudo aquilo com que, de hora em hora, os meios de informação actuais excitam, surpreendem, estimulam a imaginação do Homem - tudo isso está hoje mais próximo do Homem do que o próprio campo à volta da quinta, do que o céu sobre a terra, do que o passar das horas do dia e da noite, do que os usos e costumes da aldeia, do que a herança do mundo da terra natal (Heidegger, 1954/ 2010, p. 16).

Heidegger comenta, numa entrevista proferida para a revista Der Spiegel e publicada após a sua morte em 1976, que a técnica arranca o homem da terra e o desenraiza cada vez mais e constata que "já não é mais na Terra que o homem vive". Segundo este pensador, o homem moderno falhou na apropriação de sua essência e consequentemente também se afastou em experienciar o seu habitar. No entanto, baseando-se nas palavras do poeta Hölderlin, o mesmo diz: "Ora, onde mora o perigo é lá que também cresce o que salva" (Hölderlin, citado por Heidegger, 1954/2010, p.37). O perigo ao qual Heidegger se refere é o do homem perder-se no modo de desencobrimento da técnica moderna $\mathrm{e}$ abandonar sua essência de homem livre, e a salvação consiste em justamente pensar sobre a essência da técnica e descobrir nela o seu perigo. O salvar não significa retirar o perigo, nesse caso abandonar o mundo tecnológico, mas pensar e questionar o perigo em sua essência, como fala o filósofo: "Quanto mais nos avizinharmos do perigo, com maior clareza começarão a brilhar os caminhos para o que salva, tanto mais questões haveremos de questionar. Pois questionar é a piedade do pensamento" (Heidegger, 1954/2010, p. 38).

Dessa forma, para Heidegger somente o pensar é capaz de enraizar o homem. Só é possível habitar quando pensamos nesse desenraizamento. E habitar, segundo Heidegger (1954/2010), é resguardar na paz de um abrigo, isto é, é um demorar-se junto às coisas, é deixar que as coisas apareçam em seu 
velamento e desvelamento, é aceitar permanecer junto ao mistério. O horizonte técnico fez o homem perder a capacidade de manter-se junto às coisas, de aceitar o mistério. O homem moderno quer explicação e utilidade para tudo que se apresenta. Nesse sentido, para que o homem possa, de fato, habitar, ou seja, enraizar-se nesse horizonte técnico é necessário saber onde se encontra historicamente, dar-se conta do que governa o mundo técnico, abrir-se para a sua essência. E isso só é possível, como mencionado anteriormente, assumindo uma atitude de serenidade em relações às coisas e abertura ao mistério.

\section{Pensando o cuidado e os modos de ser na era virtual}

Quando a tecnologia e o dinheiro tiverem conquistado o mundo; quando qualquer acontecimento em qualquer lugar e a qualquer tempo se tiver tornado acessível com rapidez; quando se puder assistir em tempo real a um atentado no ocidente e a um concerto sinfônico no Oriente; quando tempo significar apenas rapidez online; quando o tempo, como história, houver desaparecido da existência de todos os povos, quando um desportista ou artista de mercado valer como grande homem de um povo; quando as cifras em milhões significarem triunfo, - então, justamente então — reviverão como fantasma as perguntas: para quê? Para onde? E agora? A decadência dos povos já terá ido tão longe, que quase não terão mais força de espírito para ver e avaliar a decadência simplesmente como... Decadência. Essa constatação nada tem a ver com pessimismo cultural, nem tampouco, com otimismo... O obscurecimento do mundo, a destruição da terra, a massificação do homem, a suspeita odiosa contra tudo que é criador e livre, já atingiu tais dimensões, que categorias tão pueris, como pessimismo e otimismo, já haverão de ter se tornado ridículas (Heidegger, 1953/1987, pp. 45-46).

Nessa passagem do livro Introdução à Metafísica (Heidegger, 1953/1987), o filósofo já prenunciava o destino ${ }^{1}$ do homem moderno e previa o avanço das tecnologias de informação, ao constatar o crescimento da rapidez da informação e o acesso aos acontecimentos em tempo real. Arriscamos dizer que se Heidegger vivesse nos dias de hoje talvez não se espantasse tanto com os rumos do homem.

Considerando que já situamos o horizonte histórico em que o homem contemporâneo se encontra, nos propomos a pensar neste tópico como se revelam os modos de ser na era virtual e quais as formas de Cuidado (Sorge), como um existencial da fenomenologia hermenêutica heideggeriana, que imperam nesse horizonte. Sabemos que o horizonte da técnica imprime determinadas experiências de sofrimento ao homem contemporâneo, como também modos de cuidar que precisam ser tematizados.

Ao olharmos para o cenário atual, não demora muito para nos darmos conta de que esta dimensão sensível e humana está sendo submetida a transformações provocadas, sobretudo, pela presença constante da técnica, da máquina, da tecnologia. Estaria o homem menos sozinho por estar cada vez mais conectado à internet? Os índices da Organização Mundial da Saúde apontam para um aumento vertiginoso de casos de depressão na atualidade, girando em torno de 300 milhões de pessoas no mundo (Organização Mundial da Saúde [OMS], 2017). Como em uma sociedade tão avançada tecnologicamente, o que também envolve os avanços nas técnicas de qualidade de vida, ainda é possível se sofrer de depressão ou de solidão?

Esse fato provoca incômodo e estranheza, principalmente se considerarmos que o homem contemporâneo tem dificuldade

\footnotetext{
${ }^{1}$ Rumo, direção, sentido.
} 
em lidar com situações que fogem ao seu controle, tais como: a solidão, o envelhecimento, o sofrimento e a morte; e que muitas vezes o aparato tecnológico nada pode fazer. No entanto, o que o homem faz diante dessa dificuldade é continuar a eliminar e abafar tudo que ameace a autonomia da técnica. Nunca foi tão presente a busca por ansiolíticos e antidepressivos como nos tempos atuais. Vivemos uma era da medicalização da vida cotidiana, cuja preocupação é eliminar os sintomas o mais rápido possível.

O homem contemporâneo não tem "tempo" para refletir sobre os sentidos/significados dos males que lhe acometem. Imerso num horizonte de imediatismo, praticidade e urgência, ele busca por soluções rápidas e "mágicas" para as suas angústias. Se pararmos para pensar nas atuais formas de sofrimento como ansiedade, pânico, depressão, déficit de atenção e hiperatividade, podemos observar como elas estão relacionadas aos modos de ser impostos pelo horizonte histórico da técnica (rapidez, controle, produção, consumo, entre outros).

É interessante pontuar que nunca estivemos tão próximos uns dos outros e ao mesmo tempo tão distantes. Embora existam vários recursos que facilitam a vida do homem contemporâneo, tornando-o conectado virtualmente ao mundo, mais "próximo" do outro, o contato pessoal está reduzido. Nesse meio a presença virtual prevalece, chegando a substituir a presença geográfica do outro, ou seja, estar e não estar-com ao mesmo tempo, em muitos lugares, com muitos outros, ou com ninguém, na problematizada "solidão", mencionada por Sá, Mattar e Rodrigues (2006). $\mathrm{O}$ ser do homem, apesar de solicitar a companhia, a presença do outro virtualmente, a cada instante, continua só. A virtualização das relações inaugura uma versão atualizada e hight-tech do clássico ditado de "estar só na multidão", que passaria a ser "estar só na multidão invisível, virtual".
Os limites já não estão tão claros, é possível alcançar qualquer pessoa a qualquer momento. Na verdade, a internet possibilita um efeito curioso, vivemos um eterno presente ${ }^{2}$. Com o contato em tempo real, há um prolongamento do aqui, para ali-adiante-agora. Ou seja, com os perfis lançados na rede, a interação pode ocorrer tanto com quem está online como com quem está off-line (o que está se tornando cada vez mais raro, já que em qualquer lugar e hora é possível acessar), dando a sensação de uma continuidade no tempo do presente. E ainda, com a internet móvel, há uma verdadeira "febre" de conexões que não param. Trocas de torpedo, mensagem via aplicativos gratuitos, acesso livre às redes sociais, a qualquer hora do dia, da noite, no trabalho, ou quando for. Há sempre alguém chamando por sua atenção, algum movimento interessante que clama pela atenção e abertura do homem. A interação simultânea ${ }^{3}$, como, por exemplo, postar algo e direcionar para 20 amigos. Quanto poder e quanta velocidade!

O ritmo que rege as interações sociais no mundo virtual é tão veloz e imediato que dificulta o processamento de suas informações como um todo por seus usuários. As postagens de milhares de pessoas ocorrem simultaneamente e com isso, torna-se difícil acessar com mais detalhamento tantas solicitações. O que se sabe é que, com um click é possível satisfazer (ou não) muita gente, inclusive a si mesmo (ou não).

Neste movimento rápido e preciso, predomina o pensamento que calcula, que coisifica; seria o pensamento da "praticidade". Nesta era da técnica, há espaço para agir, responder, ser veloz e imediato. Publico aqui, recebo um curtir em menos de um segundo. $\mathrm{E}$ assim, o espaço para meditar se dilui, se desrealiza, se oculta, já que toca uma dimensão mais profunda de entrar em contato com a própria existência em meio aos demais entes, com seus silêncios, seus vazios, seus "ter que esperar uma resposta", suas frustrações e as angústias do "querer, mas não saber", da falta de controle e da imprevisibilidade que é a

\footnotetext{
${ }^{2}$ Grifo nosso.
}

${ }^{3}$ Grifo nosso. 
existência, o lançamento no mundo. Pensar, refletir e meditar vem se tornando tarefas raras e dispendiosas, visto que tudo se encontra pronto, dado, encapsulado - opiniões, pensamentos e ideias.

Interagir em tempo real aponta para a questão da existência, e a instantaneidade no virtual pode ser uma forma de evitar a solidão e a angústia. $\mathrm{O}$ homem está a todo o tempo reafirmando sua existência para o outro, para o público invisível que está do outro lado da tela e, com isso, evitando não apenas o isolamento, mas o fato de ser-para-a-morte. Sobre essa questão, Brum (2013) afirma que atualmente ouvimos muito e falamos muito, mas não sabemos se estamos escutando e dizendo algo realmente ou se isso é apenas ruído para preencher nosso vazio. Vazio que faz parte da condição de vulnerabilidade e de finitude do Dasein, o qual exige de nós aproximação e meditação, já que é impossível eliminá-lo. Assim:

Vivemos, portanto, de um modo ambivalente, a busca de afastamento (ao menos daqueles que nos soam como estranhos) e a necessidade de proximidade. Aspiramos estar entre iguais, nos sentir seguros e confortáveis, amparados e protegidos. Mas, para isso, o outro é desvelado como um "algo" colocado a nossa disposição, devendo atender aos nossos desejos, saciar a nossa "sede", dar conta do vazio que sentimos. Os nossos esforços parecem improfícuos, já que o distanciamento existencial persiste, e, mais do que isso, continuamente aprofunda-se (Sá, Mattar \& Rodrigues, 2006, p. 119).

Neste cenário, nos parece que o outro é visto como fonte de reserva para o uso, reduzse o ser-com-o-outro ao mundo das ocupações, isto é, estabeleço uma relação utilitarista com o outro. Sobre essa questão Heidegger (1927/1989) nos convida a pensar sobre a noção de cuidado (Sorge) enquanto um existencial. Segundo este pensador, cuidado refere-se à condição do Dasein de abertura, de estar lançado no mundo em meio aos outros entes, vivendo numa trama de sentidos. Assim, cuidado é a característica ontológica do Dasein de estar sempre referido a outro ente.

Heidegger (1927/1989) diferencia dois modos de cuidado: o da ocupação (Besorgen) que se refere às relações que o Dasein estabelece com entes cujo modo de ser é simplesmente dado; e o da preocupação (Fürsorge) que se refere às relações que o Dasein estabelece com outros Daseins. No cotidiano impessoal o modo de cuidado que prevalece nas relações humanas é o da indiferença. Este caracteriza-se por um não se importar com os outros, sendo marcado por uma naturalização dos sentidos e nivelamento das diferenças. Embora seja um cuidado no modo da preocupação por se referir a outros Daseins, estas características também marcam o modo da ocupação com as coisas, como nos referimos no parágrafo anterior, ao modo utilitarista que o homem contemporâneo se relaciona/se ocupa com os outros.

Ainda sobre os modos de cuidado Heidegger fala sobre duas possibilidades da preocupação. Ele afirma que a preocupação pode se dar por substituição, isto é, substituo o outro em seus "afazeres", faço por ele. Nesse modo o outro pode tornar-se dependente e dominado, e aqui cabe um paralelo com as nossas reflexões no mundo virtual. Quantas vezes nós não deixamos a cargo do virtual os nossos afazeres? Quantas vezes nos desresponsabilizamos por nossos atos e nos escondemos atrás do nosso perfil nas redes sociais? Segundo Critelli (2002) a técnica nos substitui em nosso cuidar de ser. Ela rouba a nossa condição e cuida por nós. A outra possibilidade é a preocupação por anteposição, nesse modo não fazemos pelo outro, mas nos colocamos diante do outro de modo que este se veja em sua abertura e liberdade para suas possibilidades mais próprias. Este, segundo Heidegger, é o cuidado propriamente dito, é quando o outro se apropria da sua existência enquanto cuidado.

Voltando às nossas reflexões no mundo virtual, no modo indiferente de cuidado o 
homem distrai-se de si para ocupar-se de entes simplesmente dados, coisificados, que se mostram na cotidianidade, principalmente através do consumo superestimulado e desenfreado e da mídia em massa (TV/internet) que diariamente traz para dentro de nossos lares e, por que não dizer, de nossos ethos, enquanto "morada" nas palavras de Andrade e Morato (2004), notícias trágicas do ser-humano banalizadas, modelos de beleza e felicidade a serem seguidos, cobranças do mundo capitalista, que primam pela objetividade, produtividade, generalização e economia do tempo.

A facilidade em adicionar $e$ deletar ${ }^{4}$ pessoas. A convivência no ambiente virtual está permeada pela noção de liberdade e poder. Então, da mesma forma que o homem encontra nesse espaço um local livre para expressar-se da forma como quiser, acessar o que quiser e fazer o que bem entender, há uma noção desmedida de poder ilimitado. Como se tudo fosse possível. De fato, quase tudo é, mas as implicações disso é que geram repercussões importantes. Até que ponto o outro pode ir? Quais são os limites na virtualidade?

Se há algum tempo atrás, conseguir o contato de uma pessoa era extremamente complicado, devendo o interessado percorrer, pelo menos, algumas listas telefônicas, ir aos correios e empreitar gastos de tempo, energia, combustível para alcançar seu alvo, hoje, como quase todo mundo está nas redes sociais, basta digitar uma palavra-chave no campo de busca, mais um click, para encontrar várias possibilidades para o que ou quem se procura. Entra em ação o poder de adicionar pessoas, conhecidos ou desconhecidos, formando uma grande rede de contatos. E assim, o homem passa a colecionar rostos em sua página inicial, com amigos em vários tipos de sentido: colegas, conhecidos, melhores amigos, família.

No continuum deste poder, está o de deletar. Com a mesma facilidade que se tem para adicionar alguém, ainda que não se conheça pessoalmente, é possível deletá-la facilmente caso alguma atitude sua desagrade. A questão talvez seja a banalização do adicionar e deletar, como se faz com as coisas simplesmente dadas. Tamanha facilidade e poder com os quais nos deparamos nesse horizonte técnico/virtual nos faz pensar que assim como fazemos com as coisas, também usamos e descartamos as pessoas de acordo com a serventia que as mesmas têm para nós e as quais também tentamos controlar e assegurar quando nos convêm. Essa descartabilidade de pessoas é preocupante, na medida em que objetivamos as relações e não estabelecemos vínculos duradouros e profundos, o que acaba por fomentar tamanha solidão em tempos de tanta interação.

Para Critelli (2006), com a sucessiva descartabilidade e reposição, características do mundo contemporâneo, há uma interferência significativa nas relações entre os homens, especialmente no tocante à retenção histórica pessoal e coletiva. Assim, assinala que: "Com o descarte dos objetos de uso, descartamos juntamente a lembrança de nossas vivências com os outros, o que equivale a dizer que descartamos essas vivências mesmas, isto é, as des-realizamos" (p.120). Isso torna as interações superficiais e carentes de aprofundamento.

Nesse modo de ser, retomando a discussão do tópico anterior, o homem encontra-se em profundo desenraizamento, isto é, não pertence a nada e nem a ninguém, não habita propriamente nenhum espaço. Podemos dizer que o avanço tecnológico compromete o modo de ser humano na medida em que retira a sua humanidade, qual seja, sua capacidade de meditar/refletir e de cuidar (cuidar em sentido próprio/ antepositivo).

Pensando a impessoalidadel impropriedade 5 tratada no quarto capítulo de Ser e tempo pelo filósofo Martin Heidegger (1927/1993), seria um modo cotidiano de mostrar-se do Dasein, dissolvido no que os outros esperam de si, agindo de acordo com as massas, com o 'todos nós', sendo, portanto,

\footnotetext{
${ }^{4}$ Grifo nosso.
}

${ }^{5}$ Grifo nosso. 
impessoal em seu modo de ser-com. Vale salientar que este modo faz parte do modo como o Dasein se manifesta no mundo, não devendo ser visto de forma negativa/valorativa, mas com uma atitude compreensiva do seu próprio poder-ser, considerando-se toda sua facticidade.

Embora as pessoas se conectem atualmente como uma forma de mostrar-se ao outro, fazendo-se existir, virtualmente, por mais paradoxal que possa parecer, observando as movimentações no mundo virtual, percebese este espaço como mais um, dentre tantos outros em que está lançado o Dasein, a favorecer a diluição de sua pessoalidade, na coletividade, por exemplo, de discursos impróprios que permeiam o âmbito das interações sociais virtuais. Com imediaticidade, técnica e facilidade, o encontro e o contato pessoal se tornam secundários. $\mathrm{O}$ Dasein vive tão conectado ali, que se desconecta do aqui.

Para Heidegger (1927/1993), no cotidiano impessoal, vivemos segundo as solicitações do mundo, partindo de convenções sociais e expectativas para as quais nós fomos criados, desde o nascimento, a atender. A sociedade clama para que todos sigam padrões: de beleza, felicidade, saúde, eficiência, relacionamentos, moda, etc. Não é possível fugir deste cenário que está aí desde o nosso nascimento. Dessa forma, no modo de ser impessoal, o sentido atribuído às coisas é transmitido pelo outro, em forma de mídia, pela publicidade, como verdades absolutas e inquestionáveis, ou seja, é transmitido pelo horizonte histórico de cada época.

A expressão do modo impessoal de ser no ambiente virtual pode ser visto nas correntes religiosas, causas animais e promoções postadas à espera de um curtir, de um compartilhamento de seu conteúdo e de um comentário. Na rede, o homem está a todo o tempo interagindo com um propósito $\mathrm{e}$ aguardando um retorno, uma resposta do outro. Além disso, virtualmente "constituído", o homem tem agora à sua disposição, com as redes sociais, em apenas um click, a possibilidade de reinventar-se, mostrar-se, revelar-se da forma como a impessoalidade, o "ideal", o "a gente" ou "todos nós", esperam que seja e se revele: gênero, idade, raça, status social, cultural, econômico, moradia.

Portanto, o homem, com os recursos das Tecnologias de Informação, vê-se com a possibilidade de mostrar-se diferente do que de fato aparenta na concretude, e se abrir ao mundo de possibilidades virtuais, sentado à frente de um aparelho tecnológico feito de plástico e metal, produzido pela técnica humana, com iluminação artificial, conectado à internet, o que torna possível, por assim dizer, que se desoculte e busque realizar-se, com garantias de impessoalidade e anonimato. Este modo de desocultamento estaria sob seu controle, já que nem sequer necessita de movimentar-se, entrar em contato com a sua corporeidade para estar-com-o-outro.

Contudo, vale lembrar que embora haja esta predominância do impróprio e do impessoal, o lado oposto, a propriedade e a pessoalidade são caminhos viáveis, ainda que mais dificultosos, por implicar em responsabilização: por si, por sua facticidade, por sua angústia e por sua solidão.

Estamos paralelamente no mundo do não concreto, mas do igualmente real $\mathrm{e}$ possível. O Dasein habita o mundo ao seu modo, e assim como todo e qualquer outro lugar, o ciberespaço ou mundo virtual, é mais uma possibilidade para se expressar e se desvelar. A virtualidade implica novos modos de ser-com. Poderíamos ousar apresentar os verbos mais conjugados na atualidade: Eu publico, tu comentas, ele tuíta, nós curtimos, vós blogais, eles compartilham. Por mais estranho que possa parecer, tais verbos expressam este ser-com-o-outro da contemporaneidade, conectado digitalmente, via internet, por notebook, computador, tablet, smartphone ou smart tv.

O Dasein, lançado num mundo de afetações, também no plano virtual, está mais conectado a cada click com a promessa de realização do seu ser. Tudo à disposição para 
ser encontrado, compartilhado, deletado, adicionado e vivenciado. Para Rendeiro (2011), o mesmo espaço virtual que permite ao Dasein encontrar e reencontrar amigos, também suscita desejos e estimula o consumo, mapeando gostos e interesses e todas as ações, ao alcance de uma tecla, um click, na promessa de que a visibilidade sane tristezas e males de nossa própria existência.

Com a rede, os espaços e a distância são encurtados, e aproximam-se virtualmente Daseins. Os outros ou todos nós, estamos conectados. Haveria do outro lado da rede alguém de fato, ou este 'todos nós' nos mostra justamente o quanto estamos sós, e o quanto esse 'todos nós', seria ninguém, realmente? Acerca disso, ressalta Critelli (2006), para os entes serem reais, não é suficiente estarem simplesmente no mundo:

Tudo o que há só chega à sua plena existência, torna-se real, quando é tirado do seu ocultamento por alguém, desocultado (desvelamento), desocultado, esse algo é acolhido e expresso através de uma linguagem (revelação), linguageado, é visto e ouvido por outros (testemunho) e testemunhado, é referenciado como verdadeiro por sua relevância pública (veracização) (p. 75).

Portanto, para que o outro exista para nós, ou para que nos tornemos "reais" para o outro, é importante que nos desvelemos, saiamos da desocultação até a veracização, o testemunho do outro de nossa própria existência. Ora, o que as redes sociais fazem se não veracizar a todo o momento a existência dos Daseins ali constituídos?

Através dos diversos meios para mostrar-se, de sair do desocultamento, com publicações e postagens do mundo vivido, particular e, até então, oculto do outro, comentários sobre o que o outro postou, compartilhamento de imagens, opiniões e vídeos, o Dasein se lança, se desvela e aguarda uma resposta, uma indicação existencial de sua pré-sença no mundo, que é legitimada através da reação do outro diante de sua movimentação no mundo virtual. Então este ciclo de realização está constantemente sendo nutrido nas redes sociais.

A partir do momento em que alguém se inscreve nas redes sociais ou qualquer que seja o recurso tecnológico de interação, ela está saindo de uma invisibilidade não apenas social, mas existencial. Sai do ocultamento de seu ser, para ser visto. Ao lançar-se no aí, revela-se, esperando que o outro leia, veja, reaja, responda, curta, compartilhe o que foi publicado. Que confirme sua existência. E esta resposta é o termômetro da relevância de sua existência na cotidianidade da virtualidade.

A técnica surge para responder demandas não apenas de subsistência, mas para aplacar o vazio, a angústia de ter tantos meios de comunicação e ainda assim sentir-se só. O homem moderno vê nos recursos das TIC's uma nova possibilidade de lançar-se ao outro e realizar-se, tentando sair do isolamento e da invisibilidade existencial que o cerca, para ser visto, reconhecido, validado em sua existência para-o-outro. Para Bauman (2008), "estar invisível equivale a estar morto" (p. 21). Assim, "tudo o que está na zona escura do nada ali permanece enquanto não receber, de alguma forma, autorização para se tornar real. E pode permanecer nessa zona escura, abandonado, esquecido, recusado" (Critelli, 2006, p.78).

Esta autorização é concedida pelo outro ser do ente, homem, que está por trás da tela, por trás dos clicks. É ele que hoje tem o poder de autorizar ou não o desvelamento do outro para si e para seu público particular. Enquanto alguns se mantêm no movimento do "todos nós", com postagens que interessam ao outro, outros, cujas postagens fogem do interesse comum, tendem a ser relegados ao esquecimento, à exclusão ou até à invisibilidade virtual.

Não estaria o uso sem reflexão, seja da mídia, da tecnologia, da internet interferindo em nossa capacidade de ir mais além, de questionar, de nos aprofundar em nossas próprias questões existenciais, as questões de 
nosso ser, de meditar no pensar, tal como refere Heidegger (1927/ 1993) quando nos apresenta os modos do pensamento que calcula, característico na era da técnica, e o pensamento que medita? Assim, a ontologia de Heidegger nos convida a fazer justamente o contrário. Reaprender a pensar, a nos dispor de todas as armaduras criadas pela visão tecnicista e objetivada, para uma abertura ao que se mostra, o que é, ao poder-ser naquele momento.

Contudo, os apelos da modernidade e da técnica nos conformes da ciência moderna, continuam a postular que sabem mais do homem do que ele mesmo, com slogans de felicidade ideal, de estilo de vida de sucesso, de liberdade, de produtividade e de ocupações mil. E assim, vai além, preenchendo as lacunas, evitando o vazio que, conforme Heidegger (1981) é caminho para uma existência mais autêntica. Na realidade, o vazio, a solidão e a angústia são tonalidades afetivas que nos permitem um afastamento das solicitações do mundo e nos colocam diante de nós mesmos, nossos projetos e aspirações. Sobre isto Sá et al. (2006) afirmam:

Apenas no silêncio da hora mais solitária, quando se cala o alarido impessoal dos desejos e representações correntes de "todo mundo", é que podemos nos pôr à escuta das demandas e dos questionamentos de sentido que nos são mais próprios e singulares (p. 121).

No entanto, preencher lacunas e vazios é uma atividade rotineira na virtualidade. Os clicks nos levam aonde o desejo permitir, mesmo que este desejo seja o de tornar-se ou poder aparecer como uma outra pessoa, com atributos fictícios criados pelo ideal do "a gente". Esta é uma possibilidade do Dasein na virtualidade: criar e recriar uma imagem ideal de si. Rendeiro (2011) assinala:

Não seria o avatar a projeção desse corpo perfeito, ativo e habilidoso, capaz de nos representar no trânsito das redes? Não por acaso se renovam os dispositivos do mundo virtual capazes de gerar bonecos, figuras, representações de nós mesmos, com detalhes que copiam ou se assemelham aos nossos traços individuais, sem obesidade ou anorexia, fakes ou "seres" para usar e identificar. O que essas imagens criadas por nós falam de nós? De certo modo, revelam o nosso temor do risco, da perda, da morte. Ilustram o nosso desejo de uma vida planejada, controlada, até certo ponto, previsível (p.261).

O mundo, por símbolos diversos, informa a todo o momento que se deve evitar a dor, o sofrimento, seja ele qual for. Que as respostas precisam ser rápidas, instantâneas. E para esta finalidade, traz respostas prontas e perfeitas para este ser, que acaba aceitando para si modelos criados pelo outro, ente outro que é o em-si-mesmado mercado do consumo, que nada sabe e nada vê deste homem real, ser de sentidos e afetação, apenas vendendo desejos descartáveis de promessa de realização deste ser, em um ciclo interminável de consumirdescartar-consumir de tudo: objetos, ideias, informações e pessoas.

\section{Considerações Finais}

Embora as maravilhas modernas tenham trazido avanços indiscutíveis à sociedade, como sugerido por Heidegger, o uso das TIC's (Tecnologias de Informação e Comunicação) precisa ser ponderado. A atitude de meditar a esse respeito, pontuada e enfatizada por Heidegger, torna-se essencial neste cenário para uma aproximação do Dasein em relação a si mesmo e ao mundo em que vivecom-os-outros, ainda que de um modo virtualizado e permeado por tecnologias.

Partindo do princípio Heideggeriano de que o homem coexiste no mundo com o outro e é um eterno devir, modificando-se em sua existência, torna-se compreensível que, em decorrência da internet e das redes sociais, foram ampliadas as possibilidades de ser-com 0 
outro no mundo hipermoderno, bem como favoreceu novos modos de ser e de cuidar. A tecnologia dispõe de novas alternativas para ser-com o outro, seja para buscar outro ente, divulgar sua existência e presença, ou para buscar a realização de seu ser, simulando, aparentando ser alguém que se gostaria de ser. A técnica hipermoderna que se mostra na utilização destes meios não só confirma a existência de seus utilizadores aos demais, a plateia invisível, como veraciza suas experiências ali lançadas e compartilhadas.

O uso da internet e, especialmente, das redes sociais, ocasiona, neste aspecto, uma padronização do contato, gerida pelo movimento de abertura do "a gente" impessoal, destacado por Heidegger (1927/1993). Assim, conectados virtualmente aos outros, ao mundo, a técnica neste contexto reflete o modo impróprio e impessoal de coexistência com o outro, preenchendo os espaços vazios próprios da existência, com o falatório, em uma utopia de controle, de previsibilidade do mundo, das coisas, dos outros. Diante disso, o silêncio e a serenidade se desvelam como possibilidades ao ser do homem de escutar-se, de aproximar-se de suas solicitações mais singulares e genuínas, do que lhe é mais próprio.

Como iremos? Para cada passo, um click, pegadas e rastros delineiam o nosso percurso em rede. Assim, dentre os desafios diários de ser-com no mundo virtual estaria o de se realizar de modo próprio e autêntico neste mundo. Encontrar-se em si mesmo e na abertura com o outro e se fazer compreensível e existente-para e com-o-outro. O limite entre a propriedade e a impropriedade neste campo de imprevisibilidades e instantaneidades é muito tênue. Informar acontecimentos de sua mundanidade pode ser um modo de realizaação, mas um modo de impropriedade que pode levar à des-realiza-ação, tornando-se encapsulados e eternizados em páginas de desconhecidos.

A Internet e o uso das redes sociais aspiram reflexões mais acuradas e ponderadas, pois geralmente o que acontece com os seres humanos para aprendermos a respeito do mundo à nossa volta é que precisamos de tempo para avaliar as consequências de determinadas modificações e inovações. Sendo a Internet uma novidade, tanto para as crianças e adolescentes de hoje, como para esta geração de adultos que a antecede, ainda sabemos muito pouco sobre os impactos da virtualização à nossa sociedade. Diante do que foi possível explorar neste artigo e considerando o eterno movimento de devir, ao invés de respostas, se desvelam novos questionamentos apresentados ao Dasein: como estou e para onde vou? Este poderia ser um início da transforma-ação de sua presença e de seus modos de ser-com- $a$ técnica.

\section{Referências}

Andrade, A. N. de, \& Morato, H. T. P. (2004).

Para uma dimensão ética da prática psicológica em instituições. Estudos de Psicologia, 9(2), 345-353. doi: 10.1590/S1413-294X2004000200017

Bauman, Z. (1998). O mal-estar da pósmodernidade. In M. Gama \& C. M. Gama, (Trad.). Rio de Janeiro: Jorge Zahar.

Bauman, Z. (2008). Vida para Consumo. In C. A. Medeiros (Trad.). Rio de Janeiro: Jorge Zahar.

Brum, E. (2013, 29 de abril). É urgente recuperar o sentido de urgência. Revista Época.
Cordeiro, R. C. (2014). Heidegger e a técnica moderna como perigo e como salvação. Aufklarung: Revista de Filosofia, 1(2), 157174. Doi: 10.15440/arf.2014.18859

Critelli, D. M. (2002). Martin Heidegger e a essência da técnica. Margem, 16, 83-89. Recuperado de http://www4.pucsp.br/margem/princ16.htm Critelli, D. M. (2006). Analítica do Sentido: Uma Aproximação e Interpretação do Real de Orientação Fenomenológica. São Paulo: Brasiliense.

Duarte, A. (2010). Vidas em Risco: Crítica do presente em Heidegger, Arendt e Foucault. Rio de Janeiro: Forense Universitária. 
Dutra, E. (2008). Afinal, o que significa o social nas práticas clínicas fenomenológico-existenciais? Estudos e Pesquisas em Psicologia, 8(2), 224-237. Recuperado de http://www.revispsi.uerj.br/v8n2/artigos/pd $\underline{\mathrm{f} / \mathrm{v} 8 \mathrm{n} 2 \mathrm{a} 08 . \mathrm{pdf}}$

Feijoo, A. M. C. (2011). A existência para além do sujeito: a crise da subjetividade moderna e suas repercussões para a possibilidade de uma clínica psicológica com fundamentos fenomenológicoexistenciais. Rio de Janeiro: Edições IFEN: Via Verita.

Heidegger, M. (1959). Serenidade. In M. M. Andrade, \& O. Santos (Trad.). Lisboa, Portugal: Instituto Piaget.

Heidegger, M. (1981). Todos nós ... ninguém. In D. M. Critelli (Trad.). São Paulo: Editora Moraes.

Heidegger, M. (1987). Introdução à metafisica. In M. Matos (Trad.). Lisboa, Portugal: Instituto Piaget. (Original publicado em 1953).

Heidegger, M. (1989). Ser e tempo: parte II ( $3^{a}$ Ed.). In M. S. Cavalcante (Trad.). Petrópolis, RJ: Vozes. (Original publicada em 1927).

Heidegger, M. (1993). Ser e tempo: parte I. Petrópolis, RJ: Vozes. (Original publicado em 1927).

Heidegger, M. (2010). Ensaios e conferências (6 $6^{\mathrm{a}}$ Ed.). In E. C. Leão, G. Fogel, \& M. S. Cavalcante (Trad.). Petrópolis, RJ: Vozes. (Original publicado em 1954)

Lipovetsky, G. (1983). A era do vazio. In M. S. Pereira \& A. L. Faria (Trad.). Gallimard: Lisboa.

Lipovetsky, G. (2004). Os tempos hipermodernos. São Paulo: Barcarolla.

Morato, H. T. P. (2013). Algumas considerações da fenomenologia existencial para a ação psicológica na prática e na pesquisa em instituições. In: C. L. B. T. Barreto, H. T. P. Morato, \& M. T. Caldas, Prática psicológica na perspectiva fenomenológica (pp. 51-76). Curitiba: Juruá.

OMS. (2017). Com depressão no topo da lista de causas de problemas de saúde, OMS lança a campanha "Vamos conversar". Recuperado de https://www.paho.org/bra/index.php?option $=$ com_content $\&$ view $=$ article $\& i d=5385: \mathrm{com}$ -depressao-no-topo-da-lista-de-causas-deproblemas-de-saude-oms-lanca-acampanha-vamos-conversar $\&$ Itemid $=839$

Portela, M. A. (2008). A crise da psicologia clínica no mundo contemporâneo. Estudos de Psicologia, Campinas, 25(1), 131-140. doi: 10.1590/S0103-166X2008000100013

Rendeiro, M. E. (2011). Orkut e Facebook: As Teias da Memória em Meio às Redes Sociais. Ciências Sociais Unisinos, 47(3), 256-262. Recuperado de http://revistas.unisinos.br/index.php/ciencia s_sociais/article/view/csu.2011.47.3.08/625

Sá, R. N. (2002). A psicoterapia e a questão da técnica. Arquivos Brasileiros de Psicologia, 54(2), 348-362. Recuperado de https://app.uff.br/slab/uploads/texto41.pdf

Sá, R. N., Mattar, C. M \& Rodrigues, J. T. (2006). Solidão e Relações Afetivas na Era da Técnica. Revista do Departamento de Psicologia, 18(2), 111-124. doi: 10.1590/S0104-80232006000200009

Sibilia, P. (2008). O Show do Eu: A Intimidade como Espetáculo. Rio de Janeiro, Nova Fronteira.

Stein, E. (2011). Introdução ao pensamento de Martin Heidegger. Porto Alegre: EDIPUCRS. 
Dados sobre os autores:

- Bianca Galván Tokuo: Psicóloga, doutoranda em Psicologia pela Universidade Federal do Rio Grande do Norte (UFRN/Brasil). Professora no Curso de Psicologia da Universidade Federal do Piauí (UFPI/Brasil).

- Elza Maria do Socorro Dutra: Psicóloga, Doutora em Psicologia pela Universidade de São Paulo (USP). Professora Titular da Universidade Federal do Rio Grande do Norte (UFRN/ Brasil).

- Melina Séfora Souza Rebouças: Psicóloga, doutora em Psicologia pela Universidade Federal do Rio Grande do Norte (UFRN). Integrante do Grupo de Estudos Subjetividade e Desenvolvimento humano GESDH/UFRN/ Brasil). 